\title{
Seguridade Social a partir de 1988: o início da proteção dos direitos sociais no Brasil
}

Wederson Rufino dos Santos

Universidade de Brasília (UnB)

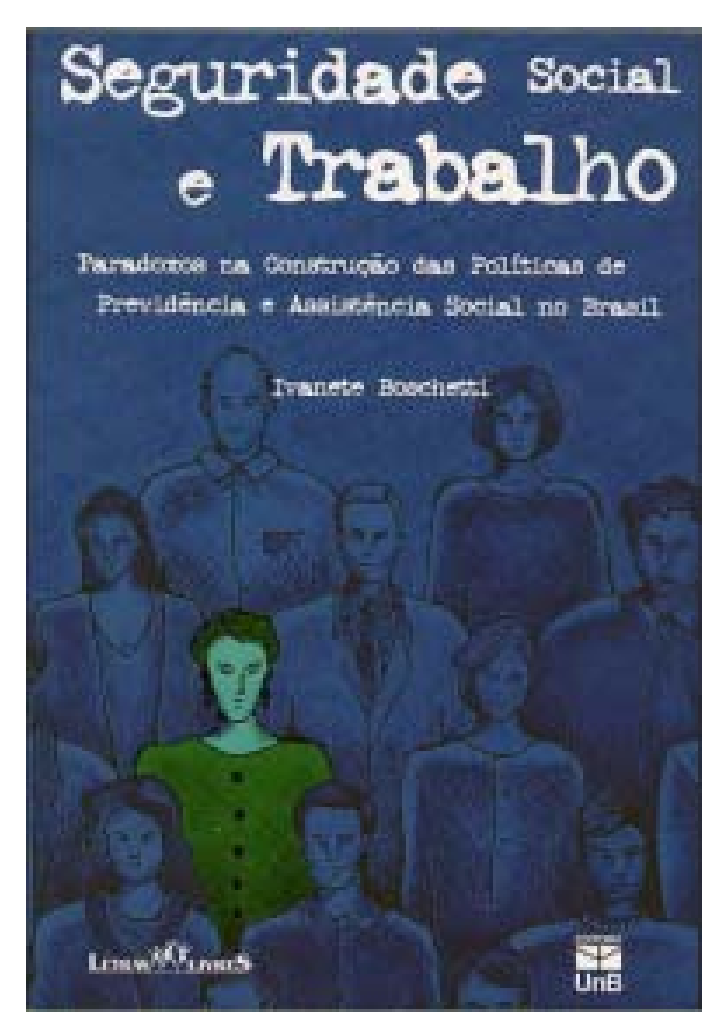

RESENHA: Seguridade Social a partir de 1988: o início da proteção dos direitos sociais no Brasil BOSCHETTI, Ivanete. Seguridade social e trabalho: paradoxos na construção das políticas de previdência e assistência social no Brasil. Brasília: LetrasLivres: Editora UnB, 2006. 324 p.

BOOK REVIEW: Social Security Since 1988: the Beginning of Protection of Social Rights in Brazil BOSCHETTI, Ivanete. Social Security and Labor: Paradoxes in the Construction of Retirement and Social Assistance Policies in Brazil. Brasília: LetrasLivres: Editora UnB, 2006. 324 p. 
As sociedades democráticas que têm a busca pela igualdade e justiça como princípio necessitam de mecanismos capazes de promover e garantir os direitos de cidadania da população. A Constituição de 1988 foi um marco quanto aos fundamentos das ações públicas para alcançar esse objetivo. O desenho da seguridade social brasileira a partir de então passou a expressar a responsabilidade do Estado democrático frente às demandas sociais e a garantir a proteção social aos sujeitos de direito.

Um dos debates mais intensos nas Ciências Econômicas e Sociais é sobre quais fundamentos políticos e teóricos o Estado deve dispor para regulamentar as atividades econômicas a fim de garantir justiça, igualdade e liberdade nas sociedades verdadeiramente democráticas. De um lado, há aqueles que acreditam que os processos produtivos por meio do crescimento econômico, de investimentos produtivos e políticas de pleno emprego, são, por si só, capazes de constituir um ambiente onde os direitos de cidadania sejam garantidos. De outro, há aqueles que defendem o contrário, situando o Estado como um agente necessário para promover a equiidade por meio da garantia dos direitos sociais - implementados pelos equipamentos da seguridade social -, já que somente os processos econômicos não conseguem assegurá-los.

É sobre a configuração da seguridade social, principalmente, o complexo previdenciário-assistencial, que trata o mais novo livro de Ivanete Boschetti, Seguridade social e trabalho: paradoxos na construção das políticas de previdência e assistência social no Brasil. Este livro tem como base a tese de doutorado da autora, concluída em 1998 na França, orientada pelo sociólogo Robert Castel, que é uma referência internacional no debate sobre trabalho e políticas de proteção social. A força dos argumentos e a experiência da autora com o tema somam-se nessa obra que, certamente, é uma das mais importantes dos últimos anos para o debate brasileiro sobre a política de seguridade social.

Segundo Boschetti, este trabalho não é somente uma análise histórica da seguridade social no Brasil, tampouco apenas uma análise da implementação da política após a promulgação da Constituição de 1988. A idéia central do livro está amparada na compreensão da filosofia e dos princípios que permitiram a associação entre as políticas de previdência e assistência social dentro da política de seguridade social prevista a partir de 1988. A obra se debruça sobre os descaminhos da estruturação tanto da previdência social, como política de proteção social dependente da condição de assalariamento da população, quanto da transformação da assistência social em direito garantido constitucionalmente.

A obra é dividida em duas partes, ambas com quatro capítulos. Os dois primeiros capítulos oferecem uma revisão rica e detalhada do processo de configuração das políticas previdenciárias e assistenciais no Brasil antes de 1988. Essa recuperação histórica e analítica permite conhecer o longo caminho percorrido pela assistência social - desde o seu surgimento nas práticas caritativas do catolicismo até chegar ao status de direito social garantido constitucionalmente. Permite, também, compreender como se deu o processo de formação das políticas previdenciárias, configuradas numa lógica de seguro e efetivadas através da contribuição do indivíduo quando passa a fazer parte do mercado formal de trabalho. Assim, a assistência social passou a ser um direito social garantido, de caráter não-contributivo, enquanto as políticas previdenciárias se constituíram em uma lógica contributiva de seguro.

De posse do processo genealógico da seguridade social no Brasil, no terceiro capítulo a autora parte para uma análise das bases sobre as quais se instalou a proteção social no país antes de 1988. É apresentado que, por meio de ações fragmentadas e inconclusas de previdência, assistência e da saúde, os poucos direitos previdenciários e de acesso à saúde pública foram se constituindo na lógica de seguro, o que, para Boschetti, esbarrou em duas contradições. A primeira delas refere-se aos acessos à saúde e aos direitos previdenciários, que, por estarem condicionados à prévia contribuição, tinham um caráter mais de direitos ligados ao trabalho do que à cidadania. A segunda contradição aponta para a exigência da contribuição em um país cujo cenário ainda não permitira uma condição salarial generalizada a toda, ou a quase toda população economicamente ativa. Esses direitos, conseqüentemente, só atingiam uma pequena parcela da população, deixando de fora um enorme contingente de desprotegidos.

No quarto capítulo, o livro discute o cenário brasileiro entre os anos de 1985 e 1988, e aponta que essa época foi decisiva para compreender o jogo de forças do período constituinte. Segundo Boschetti, compreender esse período da história do país é fundamental para entender a passagem de vinte anos de ditadura militar para a democracia. A perpetuação de determinadas oligarquias políticas no poder, aliada ao desenvolvimento econômico e social desigual durante os governos militares, contribuiu para influenciar o esboço de proteção social que se pretendia construir no Brasil com a nova Constituição, conclui a autora.

A análise do período constituinte, um dos pontos fortes do livro, é tema do quinto capítulo. Boschetti revive a efervescência política e participativa do período com os debates, as diferenciadas representações políticas e ideológicas na arena democrática da constituinte e a participação popular nas discussões que levaram à consolidação da seguridade social na Constituição. Havia uma busca por uma nova Constituição capaz de oferecer condições concretas para a realiza- 
ção de um país justo, democrático e igualitário, transformando o espaço da constituinte em um momento singular na história do Brasil. A obra discute que a participação popular, fortalecendo o caráter democrático que se objetivava construir a partir de então, e, sobretudo, a manifestação explícita das forças políticas presentes no país, são exemplos da importância do período da constituinte para a seguridade social.

Esse longo percurso histórico que culminou na constituição de 1988 estrutura o terreno para as partes mais analíticas da obra. Os capítulos seis e sete analisam o jogo de forças envolvido na regulamentação da assistência social no Brasil e na elaboração da Lei Orgânica da Assistência Social, aprovada em 1993. O conflituoso processo de discussão e elaboração do projeto de lei que regulamentaria a assistência social pode ser explicado ora pelo desinteresse da classe política em efetivá-la como direito - uma vez que poria um fim ao uso da política como instrumento clientelista -, ora pela tentativa de ampliar - a partir do firmado na Constituição - o escopo e o alcance da assistência social como uma política capaz de combater a pobreza e a desigualdade.

O último capítulo do livro mostra o perfil da seguridade social depois desse demorado e conflituoso processo de construção. A saúde e a assistência social deixaram finalmente de ter apenas aquele caráter vinculado aos direitos do trabalho. Enquanto isso, a saúde universalizada, a assistência social focalizada nos mais pobres e a previdência somente para os trabalhadores do mercado formal passaram a constituir direitos sociais resultantes dos direitos à cidadania, proteção social, e das ações de combate à pobreza. Boschetti aponta que, muito embora, esses avanços na seguridade social tenham sido firmados na Constituição de 1988, ainda se apresentam como políticas pouco eficientes no tocante à redução da pobreza e da desigualdade socioeconômica persistentes no Brasil.

O debate existente nas Ciências Sociais e Econômicas em torno do grau de intervenção do Estado nos processos produtivos necessários para se alcançar justiça e eqüidade denunciam as diferentes forças políticas e ideológicas presentes no país. As dificuldades, tanto na construção quanto na implementação da seguridade social a partir de 1988, são exemplos do controverso debate sobre o papel do Estado democrático brasileiro. Os fundamentos da seguridade social brasileira afirmam que as forças econômicas não são suficientes para garantir os direitos de cidadania, relegando ao Estado a responsabilidade em manter uma rede de proteção social àqueles que não acessam as vantagens produzidas pelo sistema econômico vigente.

No entanto, antes de se implementar de fato essa proteção social, ela já vem sofrendo mudanças que resultam em retrocessos. As reformas da previdên- cia de 1998 e 2003, sob as justificativas orçamentárias e do suposto déficit fiscal, bem como a dificuldade de transformar a assistência em política fortalecida que de fato combata a desigualdade, são alguns dos exemplos de retrocesso sofrido pela seguridade social antes mesmo dela se tornar uma realidade. $\mathrm{O}$ novo livro de Ivanete Boschetti resgata com qualidade teórica essa discussão e traz para o centro do debate brasileiro a necessidade de reafirmar a seguridade social como instrumento fundamental, capaz de promover justiça e igualdade no país.

\section{Wederson Rufino dos Santos}

Assistente Social

Membro do Grupo de Pesquisas Ética, Saúde e Desigualdade Social, do Departamento de Serviço Social da UnB

Pesquisador da ANIS: Instituto de Bioética, Direitos Humanos e Gênero

Endereço: ANIS-Instituto de Bioética, Direitos Humanos e Gênero

Caixa Postal: 8011

Brasília - DF

CEP: 70673-970 